\title{
Conditioned galvanic skin response in the chick embryo: Preliminary report
}

ROBERT FRIED AND SUSAN GLUCK HUNTER COLLEGE OF THE CITY UNIVERSITY OF NEW YORK ${ }^{1}$.

Two 14 day old chick embryos were conditioned to a tone associated with a shock. Definite changes were noted in the GSR records obtained from the Ss. Similar findings were also obtained for $15,16,17$, and 18 day old embryos.

There is, to date, relatively little data on prenatal conditioning. This is surprising since, in the prenatal organism, one would expect to obtain, under certain conditions, maximum control over stimulus conditions.

Conditionability has been thought to have its onset, in humans, variously between the tenth day and fifth month, postnatal (Marquis, 1931; Wickens \& Wickens, 1939). Similar findings have been reported with neonate rats (Caldwell \& Werboff, 1963), canine pups (Cornwell \& Fuller, 1961), and in pigeons (Tsuge \& Shima, 1959).

There is some evidence of conditioning at the embryonic level. Spelt (1938) reports positive results working with human fetus, in utero, and Gus (1932) with birds. However, the most impressive findings, and those most relevant to the present study, are the data of Hunt (1949) obtained from fetal chicks. In that study, Hunt conditioned the chicks to the ring of a bell. Approximately $70 \%$ of his Ss showed definite responses to the tone of the bell. The responses consisted of leg movement, recorded on a kymograph.

Leg movement is, however, not the most precise measure since there is a large number of spontaneous movements of this kind. And, in a series of pilot studies preceding the present study, it was found that the spontaneity and irrelevance of unelicited limb movements render this index of conditioning relatively unstable. For this reason, the galvanic skin response (GSR) was chosen instead.

Using the method described below, GSR measures have been obtained, variously, from the leg of the chick embryo and the rat fetus. It was found that spontaneous leg movement, while it does affect GSR measures, produces relatively small deflections compared to those proportional to angular limb displacement.

The purpose of the present study is to demonstrate the acquisition of an aversive conditioned response in the 14 day old chick embryo.

Method

Subjects. The Ss were two 14 day old chick embryos.

Procedure. Two dozen fertile eggs were incubated in a cornmercial incubator (Sears, Roebuck, Inc.) at temperatures ranging from $99.5^{\circ} \mathrm{F}$ to $101.5^{\circ} \mathrm{F}$, at approximately $85 \%$ humidity.
On the fourteenth day of embryonic development, two eggs were removed from the incubator and fenestrated. The opening was approximately 1 in. diameter. Amnionic membranes were resected and the embryo rotated until a leg was presented. Electrodes, consisting of two small rubber tubes through which wire loops were inserted, were placed over the leg so that the loops conformed to the portion of the limb encircled.

Conditioning procedures were carried out in a standard sound-proof test chamber. Preconditioning consisted of 20 presentations of the CS (500 cps tone) presented through an earphone in proximity to the $S$, of 5 sec. duration, at 30 sec. intervals. GSR adaptation patterns and procedures were similar to those previously reported in a study with human Ss (Fried, Korn, \& Welch, in press).

The UCS, a $20 \mathrm{v}$ ac shock, delivered through the electrodes used to monitor GSR, was presented for 5 sec., its onset contiguous with the termination of the CS.

Acquisition consisted of 10 blocks of CS-UCS pairs, each followed by one test trial (with the CS only). These 50 trials were followed by a 20 min. rest period following

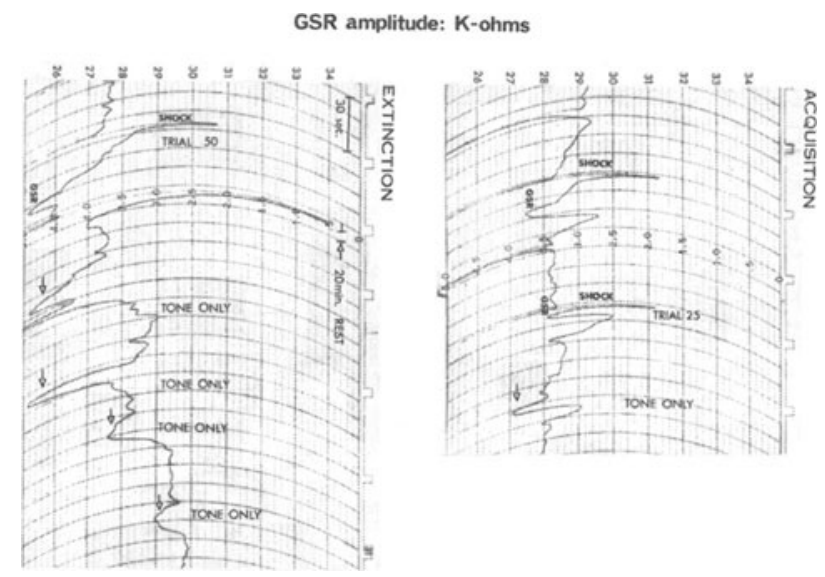


which the CS was presented five times to determine whether it had acquired aversive properties as indicated by changes in skin impedance.

The procedure was also carried out with other Ss on the 15th, 16th, 17th and 18th days. However, only the results obtained on the 14th day are reported since strong evidence for conditioning was obtained from virtually all Ss.

\section{Resulis}

Typical results are shown in Fig. 1. Two segments of the record for one $S$ are presented. The large and rapid deflections indicate the administration of the shock: the electrodes were disconnected from the GSR apparatus to avoid damage to the recorder. A gradual decrease in GSR baseline and amplitude may be noted as well as a distinct CR as early as the first unreinforced test trial following trial 15. Note, also, the gradual decrease in GSR amplitude during the extinction phase, in response to unreinforced trials.

While these data represent $S_{1}$, they are sufficient to illustrate the findings since the other records are essentially similar.

\section{Discussion}

There is substantial evidence, in the present findings, to indicate that aversive GSR conditioning is demonstrable in the chick embryo as early as the 14th day of development.

The data further indicate that prenatal conditioning is not apparently different from postnatal conditioning. Pre-conditioning procedures, used to adapt the organism to the CS, follow a pattern similar to that observed in other organisms and both these data and the response decrement in the extinction portion of the conditioning procedure suggest that the observed phenomena are the result of conditioning and not of sensitization.

\section{References}

Caldwell, D. F., \& Werboff, J. Classical conditioning in newborn rats. Science, $1963,136,1118-1119$.

Cornwell, A. C., \& Fuller, J. L. Conditioned responses in young puppies. J. comp. physiol. Psychol., 1961, 54, 13-15.

Gus, M. Les reflexes conditionnels chez l'embrion d' oiseau. Bull. Soc. Sci., Liege, 1935, 4, 195-199.

Fried, R., Korn, S., \& Welch, L. The effects of change in sequential visual stimuli on GSR adaptation. J. exp. Psychol., in press.

Hunt, E. L. Establishment of conditioned responses in chick embryos. J. comp. physiol. Psychol., 1949, 42, 107-117.

Marquis, D. P. Can conditioned responses be established in newborn infants. J. gen. Psychol., 1931, 39, 479-492.

Spelt, D. K. Conditioned responses in human fetus. Psychol. Bull., 1938, 35, 712-713.

Tsuge, K. H., \& Shima, I. Ontogenesis of conditioned defensive reflexes in young pigeons. Zh. vyssh. nervn. Deyatel., 1959, 451-460.

Wickens, D., \& Wickens, C. A study of conditioning in neonates. Psychol. Bull., 1939, 36, 599.

\section{Hote}

1. Also The Payne Whitney Clinic, New York Hospital Cornell Medical Center. 